\title{
Gene Expression Changes in Colorectal Cancer during Metronomic Chemotherapy and High-Concentration Drug Administration
}

\author{
Panagiotis Apostolou ${ }^{1}$, Maria Toloudi ${ }^{1}$, Irene Kalliara ${ }^{1}$, Vasiliki Kipourou ${ }^{1}$, \\ Ioanna Tourna ${ }^{2}$, Ioannis Papasotiriou ${ }^{1^{*}}$ \\ ${ }^{1}$ Research Genetic Cancer Centre Ltd. (R.G.C.C. Ltd.), Florina, Greece \\ ${ }^{2}$ Former Employee in R.G.C.C. Ltd., Florina, Greece \\ Email: ${ }^{*}$ office@rgcc.genlab.com
}

Received 19 June 2015; accepted 25 July 2015; published 28 July 2015

Copyright (C) 2015 by authors and Scientific Research Publishing Inc.

This work is licensed under the Creative Commons Attribution International License (CC BY). http://creativecommons.org/licenses/by/4.0/

(c) (i) Open Access

\begin{abstract}
5-fluorouracil (5-FU) and oxaliplatin, either alone or in combination, are widely used in chemotherapy for advanced colorectal cancer. Among chemotherapeutic strategies, metronomic chemotherapy has recently demonstrated promising efficacy against otherwise chemoresistant neoplasms. However, data on the efficacy of metronomic applications in cancer stem cells are lacking. This cell population is characterized by resistance to most chemotherapeutic models. In this study, we investigated the efficacy of metronomic chemotherapy and compared it with high-concentration administration of 5-FU and oxaliplatin and their combination in colon adenocarcinoma cells and colon cancer stem cells. We assessed changes in expression levels of specific genes involved in 5-FU and oxaliplatin resistance (thymidylate synthase, DNA (cytosine-5)-methyltransferase 1, dihydrofolate reductase, serine hydroxymethyltransferase, DNA excision repair protein, dihydropyrimidine dehydrogenase) in relation to drug administration schedule using quantitative real-time polymerase chain reaction. We also examined changes in cell viability. Metronomic chemotherapy showed greater efficacy in gene expression levels in colorectal cancer cells, while high, singleconcentration administration was more effective in colon cancer stem cells. Regarding cell viability, no significant change was observed between metronomic and single-dose treatments. These results suggest that metronomic chemotherapy may be more effective than high-dose chemotherapy in some patients with colorectal cancer, though high, single-concentration administration may be more effective against cancer stem cells.
\end{abstract}

\footnotetext{
"Corresponding author.
}

How to cite this paper: Apostolou, P., Toloudi, M., Kalliara, I., Kipourou, V., Tourna, I. and Papasotiriou, I. (2015) Gene Expression Changes in Colorectal Cancer during Metronomic Chemotherapy and High-Concentration Drug Administration. Journal of Cancer Therapy, 6, 679-689. http://dx.doi.org/10.4236/jct.2015.68075 


\section{Keywords}

\section{Metronomic Chemotherapy, 5-Fluorouracil, Oxaliplatin, Colorectal Cancer, Cancer Stem Cell}

\section{Introduction}

Colorectal cancer (CRC) is the third most common cancer worldwide, with a high morbidity. Although recent improvements in access to and use of screening have led to reductions in CRC death rates [1], resistance to chemotherapy and chemotherapy-related side effects remain major problems [2]. The chemotherapeutic agents used to treat CRC include 5-fluorouracil (5-FU), oxaliplatin, irinotecan, fluoropyrimidines, and other small molecule drugs, used either as monotherapy or in combination [3]. The combination of 5-FU and oxaliplatin is one of the most commonly used combinations. However, some studies found that monotherapy was more effective than the combination [4] [5], while other evidences suggested that the metronomic application of chemotherapy, i.e., continuous administration of low-dose chemotherapeutic agents without extended intervals, could be more efficient [6]. Resistance to chemotherapy may be associated with the existence of cancer stem cells (CSCs), which comprise a subpopulation of circulating tumor cells that may detach from the primary tumor and enter the blood circulation, thus creating secondary tumors [7] [8]. Circulating tumor cells usually express specific genes associated with drug resistance, such as multidrug-resistance related proteins, or aldehyde dehydrogenase [9], while CSCs are also chemoresistant and express ABC transporters [10].

The present study aimed to investigate the effects of 5-FU and oxaliplatin as monotherapy or in combination in CRC and colon CSCs lines and to compare single high-concentration and metronomic applications.

\section{Materials and Methods}

\subsection{Cell Lines and Culture Conditions}

The human (parental) colon CSC line (36112-39P) was obtained from Celprogen Inc. (San Pedro, CA, USA). Cells were cultured in $25 \mathrm{~cm}^{2}$ flasks in Human (Parental) Colon Cancer Stem Cell Culture Serum-Free Medium (M36112-39P; Celprogen). HCT-116 colon adenocarcinoma cells were obtained from the European Collection of Cell Cultures (UK). Cells were cultured in the indicated culture medium with the appropriate amount of heatinactivated fetal bovine serum (S0615; Biochrom, UK) and $2 \mathrm{mM}$ L-glutamine (G7513, Sigma, Germany) in a humidified incubator at $37^{\circ} \mathrm{C}$ with $95 \% \mathrm{O}_{2}$ and $5 \% \mathrm{CO}_{2}$. Supplements were added to the same culture medium every day. The cells were obtained by trypsinization with $0.25 \%$ trypsin-EDTA (25200-072; Invitrogen, CA, USA). All experiments were performed after 0, 24, 48, 72, 144, 168, 192, 216 and $240 \mathrm{~h}$ of treatment with the agents, respectively.

\subsection{Anticancer Agents}

5-FU (F6627) was obtained from Sigma Aldrich (St. Louis, MO, USA) and reconstituted in ammonium hydroxide to a final concentration of $50 \mu \mathrm{M}$ for single dose and $500 \mathrm{nM}$ for metronomic application, and stored at $4^{\circ} \mathrm{C}$ until required. The same procedure was followed for oxaliplatin (O9512; Sigma Aldrich), which was reconstituted in distilled water to final concentrations of $1.12 \mu \mathrm{M}$ and $11.2 \mathrm{nM}$, respectively.

\subsection{Cell Treatment and Exposure Time}

The drug concentrations used in most of the combination studies were based on the $\mathrm{IC}_{50}$ values, characterized as the drug concentration responsible for $50 \%$ growth inhibition. The concentrations of drugs used in this study were lower than those used in clinical practice as part of the metronomic test. To determine the cytotoxicity of each agent alone and in combination within a time window of $240 \mathrm{~h}$, each cell line was cultivated in $25 \mathrm{~cm}^{2}$ flasks (nine flasks in total) and incubated for $0,24,48,72,144,168,192,216$ and $240 \mathrm{~h}$, respectively, at $37^{\circ} \mathrm{C}$. Treatment was started the day after plating using $500 \mathrm{nM} 5$-FU and $11.2 \mathrm{nM}$ oxaliplatin. One cell population was treated with 5-FU alone, a second population was treated with oxaliplatin alone, and a third population was treated with 5-FU and oxaliplatin in combination. Treatments were administered every day using the same con- 
centrations of agents. Untreated cells were used as controls. At the end of each incubation period, cytotoxicity was evaluated by determining the cell number using a Nucleo-Counter NC-100 (ChemoMetec A/S, Denmark) and the expression levels of specific genes were measured.

\subsection{Quantitative Real-Time Polymerase Chain Reaction}

Total RNA was extracted from treated and untreated cells using an RNeasy mini kit (74105; Qiagen, Germany). RNA samples were evaluated spectrophotometrically and by checking the 18-28S bands by agarose gel electrophoresis. RNA $(1 \mu \mathrm{g})$ was used as a template for cDNA synthesis using an iScript cDNA synthesis kit (1708891; Bio-Rad, Italy). The above strand was used as a template for quantitative real-time polymerase chain reaction (qPCR) (50 ng per reaction), which was performed using iTaq Universal SYBR Green Supermix (1725124; Bio-Rad). Specific primers for each marker (TYMS, DNMT1, DHFR, SHMT1, ERCC1, DPYD) and for the endogenous control gene (18S rRNA) were designed using Genamics Expression 1.1 software (Genamics, Hamilton, New Zealand). The sequence of primers was run on BLAST to exclude those that amplified undesired genes (Table 1). The PCR reaction program was as follows: initial denaturation at $95^{\circ} \mathrm{C}, 50$ cycles of denaturation at $95^{\circ} \mathrm{C}$ for $10 \mathrm{~s}$, followed by annealing at $59^{\circ} \mathrm{C}$ for $30 \mathrm{~s}$. A final extension step was performed at $72^{\circ} \mathrm{C}$ for $10 \mathrm{~min}$ followed by melting curve analysis. Data were analyzed according to the Livak method [11].

\subsection{Cell Viability}

The number of viable cells after exposure to the drugs was determined using a NucleoCounter NC-100 image cytometer. This technology is based on the detection of fluorescence from DNA-bound fluorescent propidium iodide. The NucleoCassette compatible with the NC-100 is able to count even highly-aggregated mammalian cells.

\subsection{Statistical Analysis}

All experiments for each assay and each cell line were performed in triplicate. Differences in effects between selected compounds were evaluated by difference of means tests. A $P$ value $<0.05$ was considered statistically significant.

Table 1. Primer pairs used for qPCR.

\begin{tabular}{|c|c|}
\hline Gene & Primer sequence $\left(5^{\prime} \rightarrow 3^{\prime}\right)$ \\
\hline \multirow[t]{2}{*}{ TYMS } & Forward: TCTGCTGACAACCAAACGTGTGTTC \\
\hline & Reverse: CCATTGGCATCCCAGATTTTCAC \\
\hline \multirow[t]{2}{*}{ SHMT1 } & Forward: CCAGAGATACTATGGCGGGACTGAG \\
\hline & Reverse: CCAGCACTGTGGGTCCAGCTTATAG \\
\hline \multirow[t]{2}{*}{ DHFR } & Forward: AGTCAGCGAGCAGGTTCTCATTGA \\
\hline & Reverse: TGGACTATGTTCCGCCCACACA \\
\hline \multirow[t]{2}{*}{ DPYD } & Forward: AGGAGGGTTTGTCACTGGCAGACT \\
\hline & Reverse: TTCTTGGCCGAAGTGGAACACAG \\
\hline \multirow[t]{2}{*}{$18 S$ rRNA } & Forward : TGCCCTATCAACTTTCGATGGTAGTC \\
\hline & Reverse: TTGGATGTGGTAGCCGTTTCTCA \\
\hline \multirow[t]{2}{*}{ DHMT1 } & Forward: CTGGACGACCCTGACCTCAAATATG \\
\hline & Reverse: CGCCTCATAACTCTCAAAGCCAGAC \\
\hline \multirow[t]{2}{*}{ ERCC1 } & Forward: GCTACCACAACCTGCACCCAGACT \\
\hline & Reverse: GCAGTCGGCCAGGATACACATCT \\
\hline
\end{tabular}




\section{Results}

\subsection{Cell Lines and Culture Conditions}

HCT116 cells showed similar degrees of confluence after treatment with single-dose 5-FU and 5-FU-oxaliplatin after 72, 144 and $192 \mathrm{~h}$ of incubation. On the other hand, the confluence levels were similar for untreated and oxaliplatin-treated cells. The effect was observed after $240 \mathrm{~h}$ of incubation. Growth inhibition was more evident in 5-FU treated cells when it administered in a single-dose. Lower effect was observed after high-concentration administration of 5-FU-oxaliplatin, while the confluence of oxaliplatin was similar to untreated cells. Regarding the metronomic application, a higher growth inhibition was observed after 144 and $240 \mathrm{~h}$ of incubation. Also, after metronomic application cells tended to form smaller and spherical colonies (Figure 1(a) and Figure 1(b)).
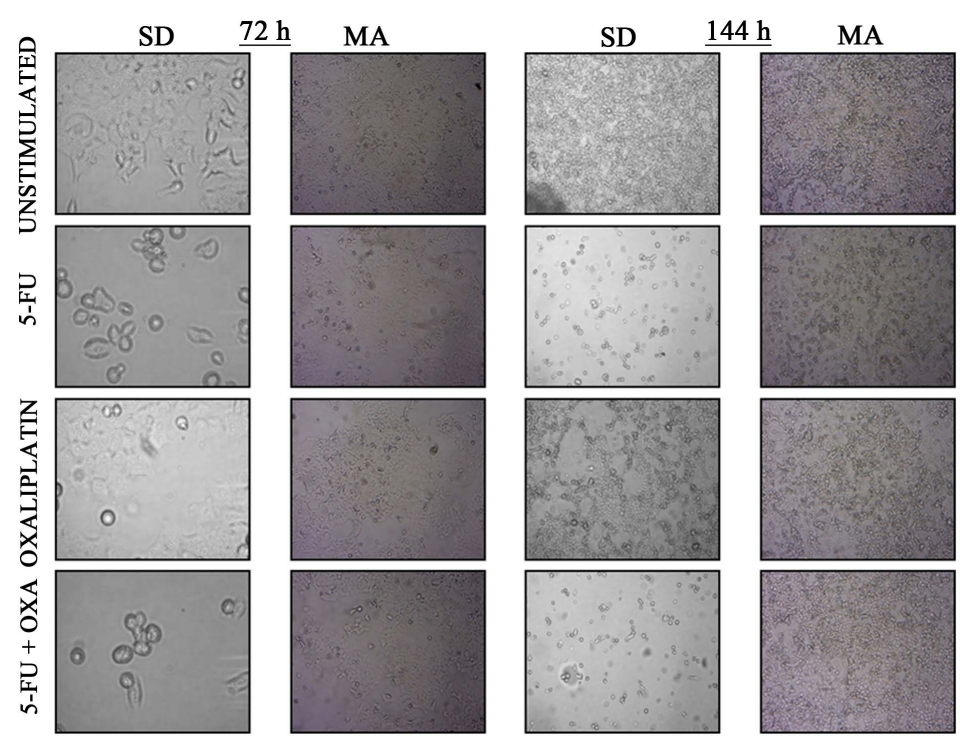

(a)
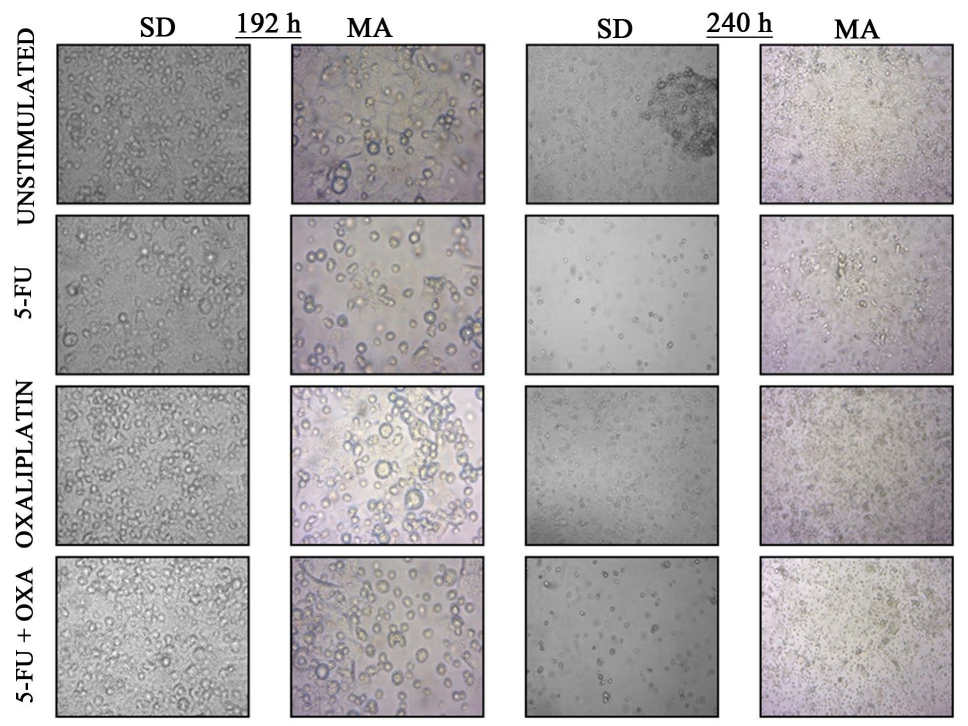

(b)

Figure 1. HCT-116 CRC cells pre- and post-treatment with 5-FU, oxaliplatin and their combination (5-FUOXA) over 240 h of incubation. Unstimulated: cells without the addition of drugs; SD: cells treated with single-dose agents; MA: metronomic application. The pictures were taken by inverted microscope using a $40 \times$ magnification. 5-FU had a final concentration of $50 \mu \mathrm{M}$ for single dose and $500 \mathrm{nM}$ for metronomic application, Oxaliplatin had a final concentration of $1.12 \mu \mathrm{M}$ and $11.2 \mathrm{nM}$, respectively. 
The results were different for colon CSCs. After single-dose administration, the impact was greater after 192 and $240 \mathrm{~h}$ of incubation. According to the chemotherapeutic agents, the growth inhibition was similar in both three conditions (5-FU, Oxaliplatin, 5-FU-Oxaliplatin). After $144 \mathrm{~h}$ of incubation an increase in growth inhibition was also observed after single administration of 5-FU-Oxaliplatin. Concerning the metronomic application, there was not observed great effect in all time periods and for all the agents. However, it is remarkable that after 144, 192 and $240 \mathrm{~h}$ of incubation with metronomic application, the cells failed to form a matrix and were almost all in suspension forming rounded single cells (Figure 2(a) and Figure 2(b)).
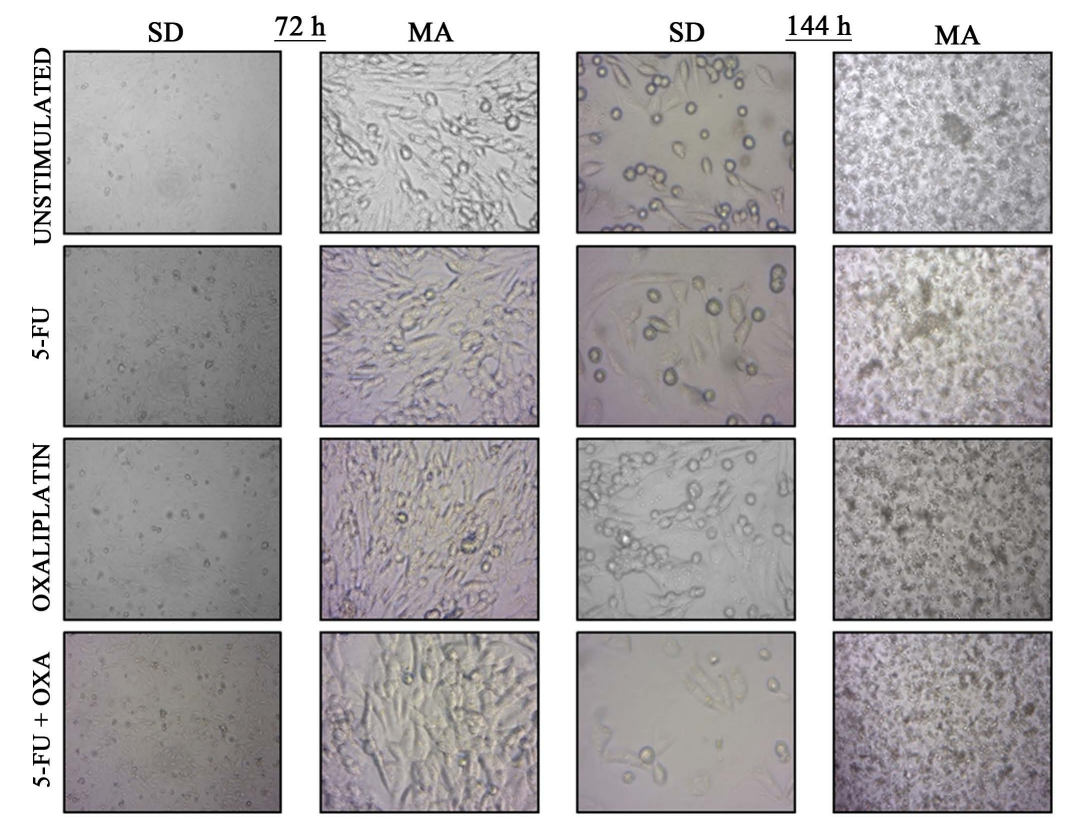

(a)

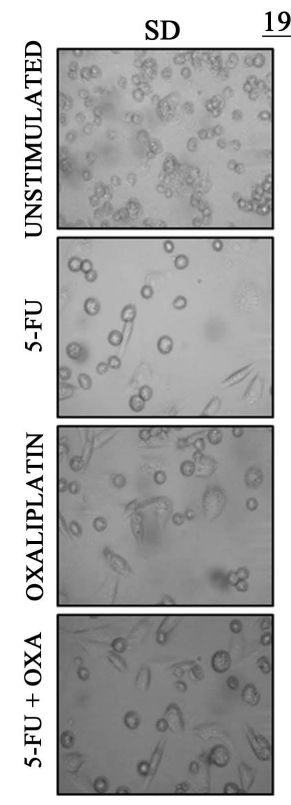

$192 \mathrm{~h} \quad$ MA
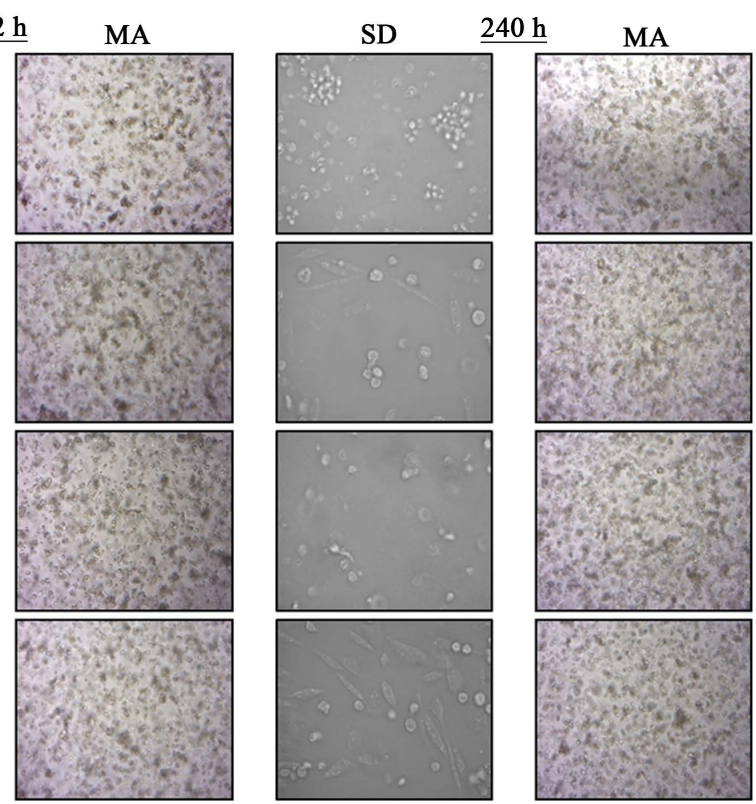

(b)

Figure 2. Colon CSC stem cells pre- and post-treatment with 5-FU, oxaliplatin and their combination (5FU-OXA) over $240 \mathrm{~h}$ of incubation. Unstimulated: cells without the addition of drugs; SD: cells treated with single-dose agents; MA: metronomic application. The pictures were taken by inverted microscope using a $40 \times$ magnification. 


\section{2. qPCR}

Expression levels of the tested genes differed in HCT-116 cells and colon CSCs according to incubation time and chemotherapeutic agents used. The greatest reduction in TYMS expression in HCT-116 cells occurred after metronomic treatment with 5-FU-oxaliplatin for $72 \mathrm{~h}$. Metronomic also had a greater effect on TYMS expression than single-use application after 144 and $192 \mathrm{~h}$. DHFR gene expression was reduced more by metronomic application after 72 and $192 \mathrm{~h}$, but the decrease was higher for single-use after 144 and $240 \mathrm{~h}$. Similar results were observed for DNMT1 and SHMT1. Regarding DPYD, a reduction in expression was only observed after $144 \mathrm{~h}$ of incubation and only with single-dose administration. Finally, the effect on ERRC1 gene expression was greater at all time periods after metronomic application compared with single-dose administration, for each drug alone and in combination (Figure 3).

No DPYD gene expression was detected in colon CSCs, and TYMS gene expression was reduced only after 192 and $240 \mathrm{~h}$ of incubation and only after single-use administration. Similar results were observed for DNMT1 and SHMT1. Regarding DHFR, the greatest reduction in expression was observed at $240 \mathrm{~h}$ after administration of single, high-concentration 5-FU. Finally, ERCC1 gene expression was only reduced by single high-concentration administration of each drug and their combination after 192 and $240 \mathrm{~h}$ of incubation (Figure 4).

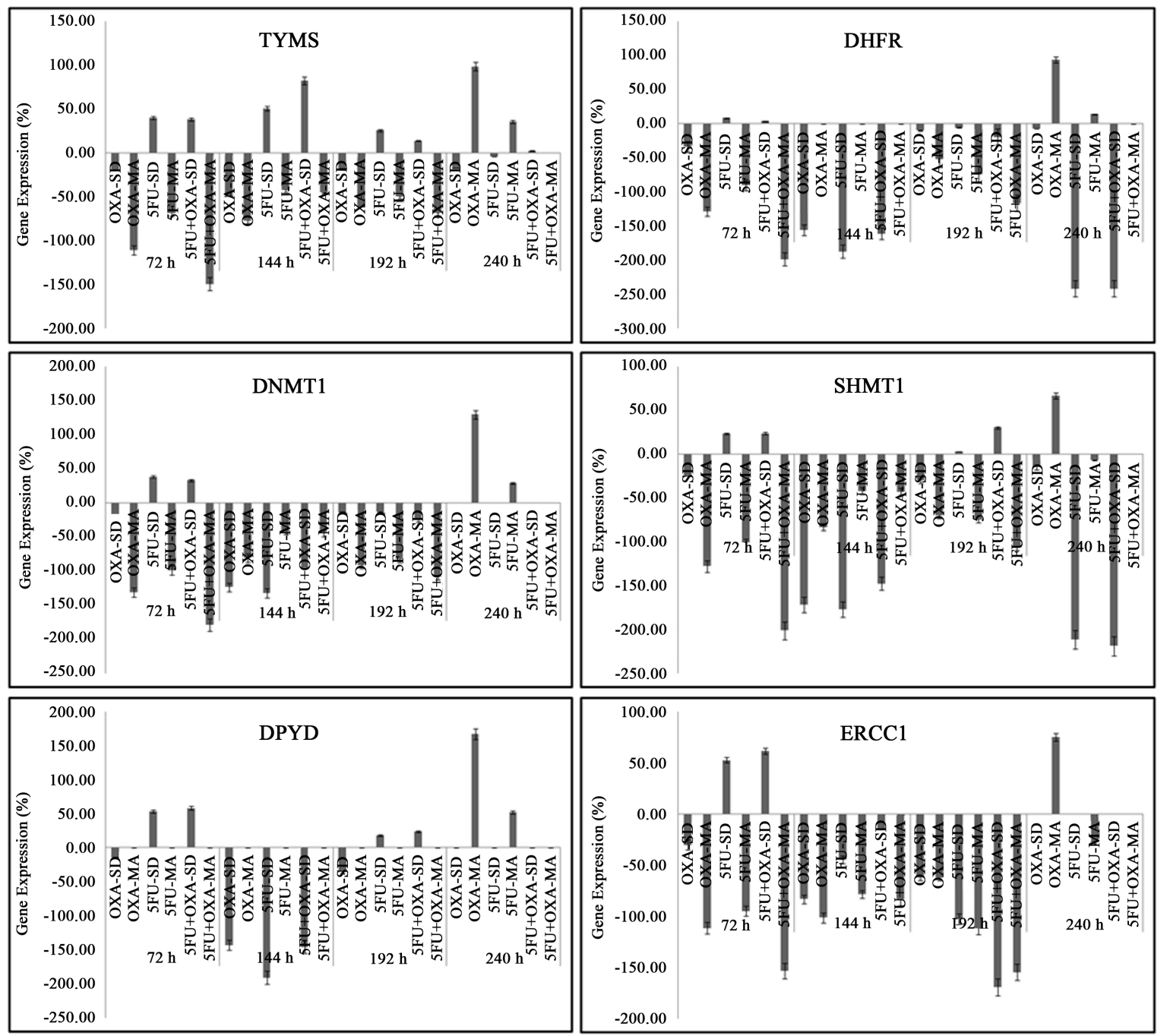

Figure 3. Gene expression analysis in HCT-116 cells. Data were normalized according to untreated samples in the appropriate time period. The data are presented as $\log 2$ ratio. Values $>0$ indicate increased gene expression, and values $<0$ indicate reduced gene expression. OXA: oxaliplatin monotherapy; 5-FU: 5-fluorouracil; 5-FU-OXA: combination of oxaliplatin and 5-fluorouracil; SD: single-dose treatment; MA: metronomic application. The statistical significance was set to 0.05 . 

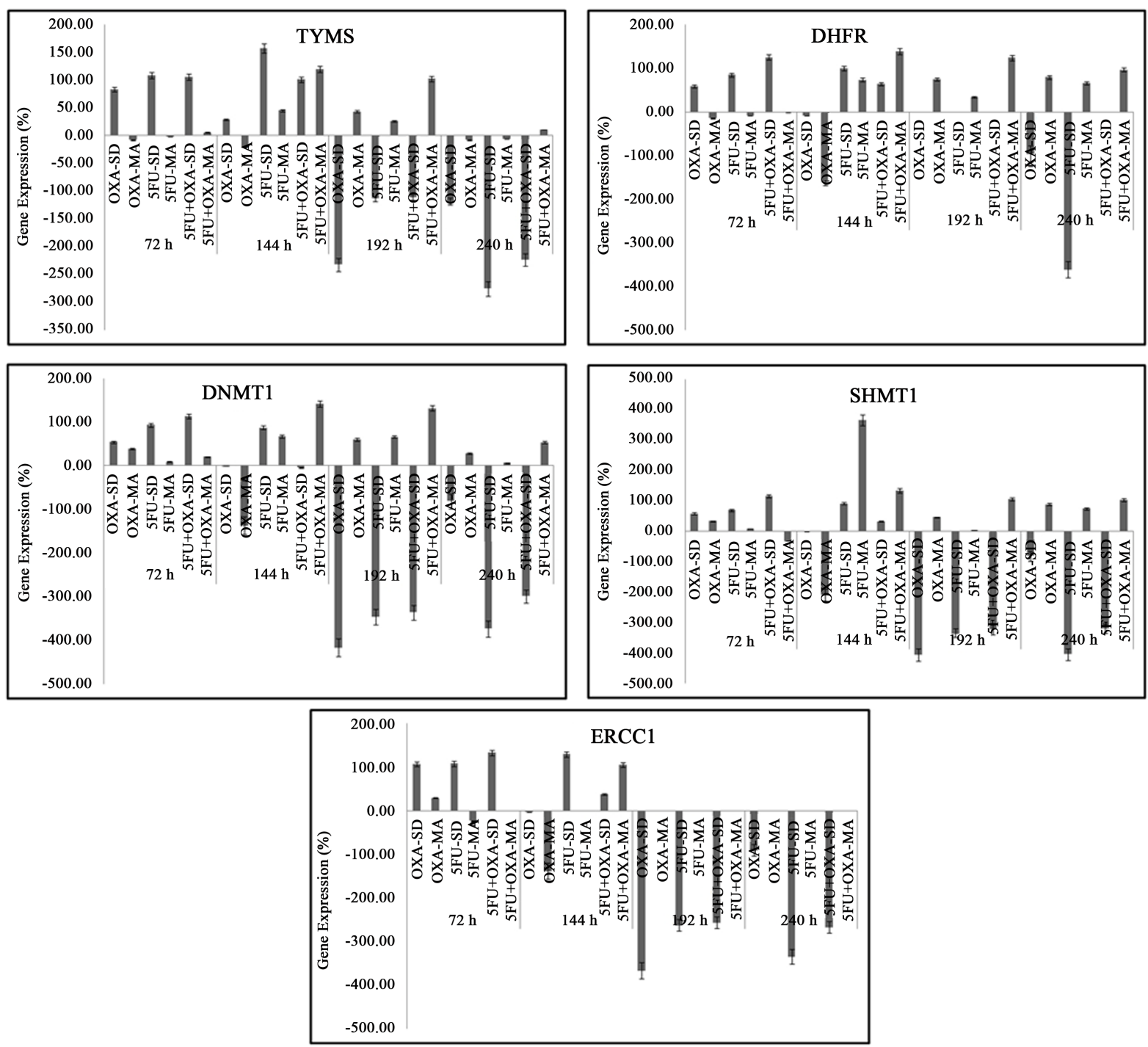

Figure 4. Gene expression analysis in colon CSCs. The data were normalized according to untreated samples in the appropriate time period. The data are presented as log2 ratio. Values $>0$ indicate increased gene expression, and values $<0$ indicate reduced gene expression. OXA: oxaliplatin monotherapy; 5-FU: 5-fluorouracil; 5-FU-OXA: combination of oxaliplatin and 5-fluorouracil; SD: single-dose treatment; MA: metronomic application. The statistical significance was set to 0.05 .

\subsection{Cell Number}

The number of viable cells was measured using a NucleoCounter NC-100 image cytometer after drug administration. The greatest decrease in HCT-116 cell numbers occurred after single high-concentration administration of the drugs alone or in combination. A decrease of up to $50 \%$ was observed after metronomic, low-dose oxaliplatin for $192 \mathrm{~h}$. The greatest effects were achieved with 5-FU and 5-FU-oxaliplatin for 144 and $192 \mathrm{~h}$ after single-dose administration (Figure 5).

The results differed in colon CSCs. Cell viability decreased by up to $85 \%$ after $72 \mathrm{~h}$ incubation with highconcentration 5-FU-oxaliplatin. Although metronomic application reduced viability, the effect was less than that achieved by high-concentration administration. In contrast, metronomic application of oxaliplatin for 144 and $192 \mathrm{~h}$ led to a decrease in cell viability of up to $80 \%$, while single-dose treatment had no effect. Metronomic application reduced cell viability after $192 \mathrm{~h}$ when the drugs were used as monotherapy or in combination. Cell number was unaffected by high-concentration therapy. After $240 \mathrm{~h}$ of incubation, the greatest reductions in cell viability were seen after administration of single-dose oxaliplatin and metronomic 5-FU (Figure 6). 


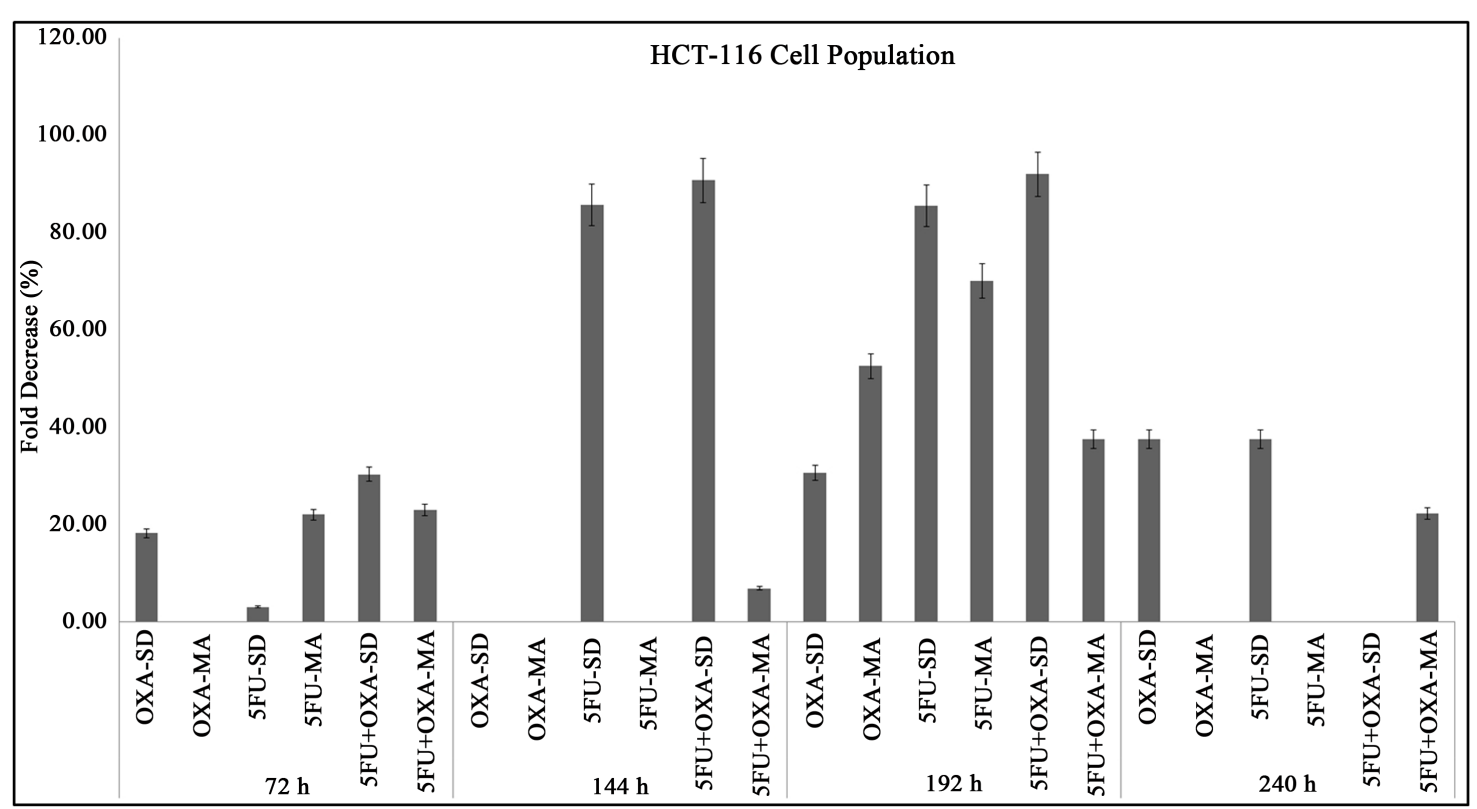

Figure 5. Cell viability of HCT-116 cells presented as fold-decrease in cell population normalized to untreated cells. Viability was assessed by propidium iodide staining. The data are presented as log2 ratio. Values $>0$ indicate increased gene expression, and values $<0$ indicate reduced gene expression. OXA: oxaliplatin monotherapy; 5-FU: 5fluorouracil; 5-FU-OXA: combination of oxaliplatin and 5-fluorouracil; SD: single-dose treatment; MA: metronomic application. The statistical significance was set to 0.05 .

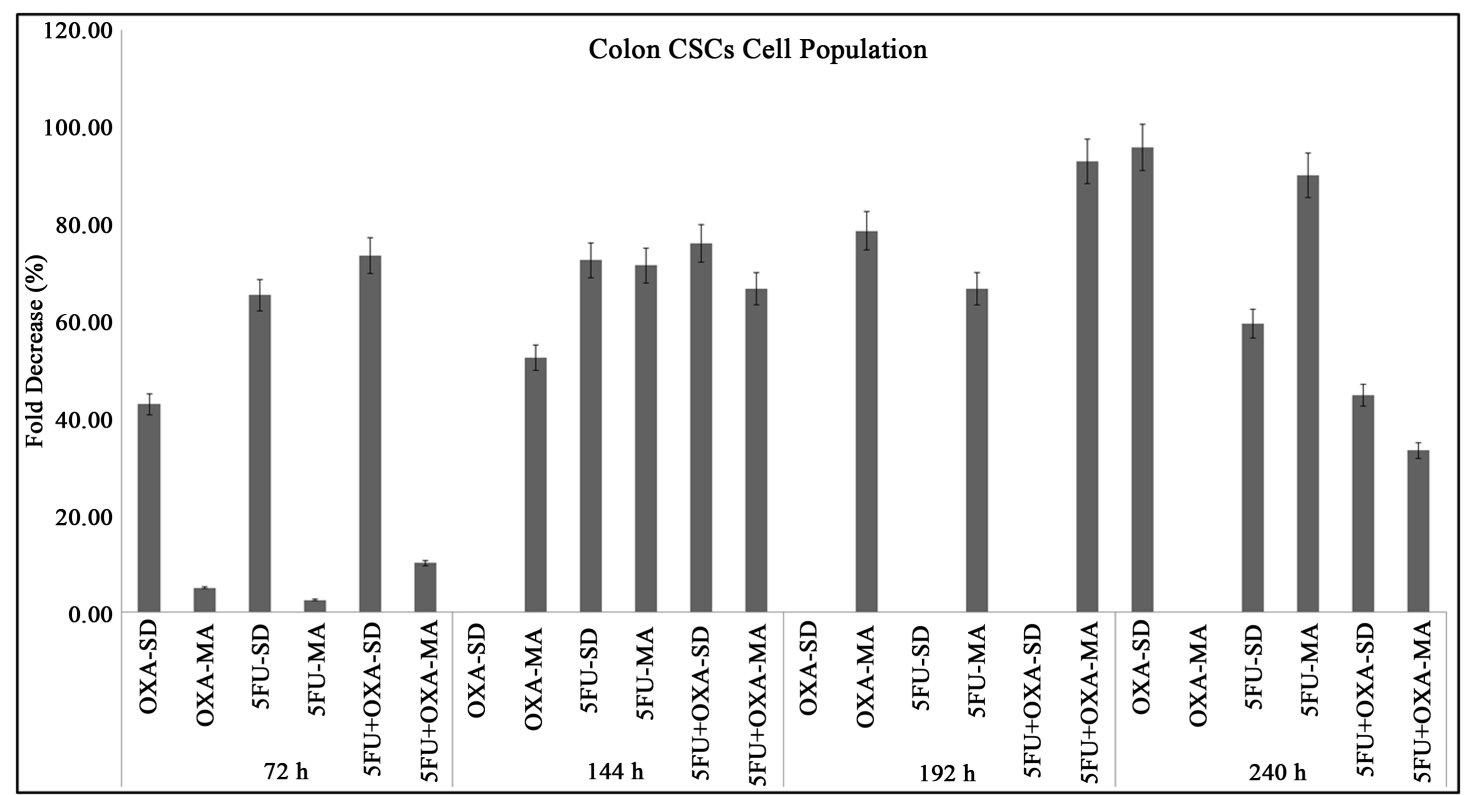

Figure 6. Cell viability of colon CSCs presented as fold-decrease in cell population normalized to untreated cells. Viability was assessed by propidium iodide staining. The data are presented as log2 ratio. Values $>0$ indicate increased gene expression, and values < 0 indicate reduced gene expression. OXA: oxaliplatin monotherapy; 5-FU: 5-fluorouracil; 5-FU-OXA: combination of oxaliplatin and 5-fluorouracil; SD: single-dose treatment; MA: metronomic application. The statistical significance was set to 0.05 .

\section{Discussion}

CRC is one of the most commonly diagnosed cancers in both men and women [12]. Platinum compounds, as well as 5-FU, are commonly used in treatment regimens for CRC. However, many patients possess or develop 
resistance to chemotherapy and radiation [13]. The presence of CSCs in the tumor may explain chemotherapy resistance, and high expression of the ABC transporter BCRP1 and O6-methylguanine-DNA-methyltransferase, which are over-expressed in CD133 cells, have been demonstrated to confer resistance to chemotherapy in these cells [14]. The scientific community has recently tried numerous approaches to overcome these problems, including administering chemotherapeutic agents at lower doses for longer periods of times, referred to as metronomic chemotherapy. Metronomic administration has been demonstrated to affect angiogenesis [15]. According to Vives et al., this method of metronomic application, followed by administration of the maximum tolerated dose, was effective in CSCs, which display anti-angiogenic properties and tumor dissemination [16]. The use of gemcitabine with metronomic 5-FU has been used as second- or third-line chemotherapy in patients with advanced adrenocortical carcinoma [17]. The metronomic application of irinotecan in CRC was more effective than administration of the maximum tolerated dose [18], and metronomically administered oral topotecan had a better impact in patients with metastatic colon cancer [19].

Overall, the above results suggest that metronomic application might be more effective than a single-maximum dose in many cases of CRC. The present in vitro pharmacodynamic study compared the effects of 5-FU and oxaliplatin and their combination on HCT116 CRC cells and colon CSCs after metronomic or single use, within a time window of 10 days. 5-FU is a pyrimidine analog that inhibits thymidylate synthase. It causes cell cycle arrest in the post-G1/pre-S phase and induces apoptosis by inhibiting DNA synthesis and interacting directly or indirectly with several enzymes [20]. 5-FU enters the cell via a facilitated nucleobase transporter and is converted to its main active metabolites FdUMP, FdUTP, and FUTP by a complex metabolic pathway. 5-FU is thought to be cytotoxic to tumor cells via three potential mechanisms: inhibition of thymidylate synthase by FdUMP, incorporation of FdUTP into DNA, and incorporation of FUTP into RNA [21]. The present study investigated the effects of drug administration on several genes encoding enzymes involved in these reactions, including TYMS, SHMT1, DNMT1, DPYD and DHFR. TYMS catalyzes the methylation of deoxyuridylate to deoxythymidine, while DPYD is responsible for the degradation of uracil and thymine. SHMT1 plays an important role in nucleic acid biosynthesis, and DHFR reduces dihydrofolic acid to tetrahydrofolic acid, the derivatives of which are essential for purine and thymidylate synthesis [22]-[25]. The effect of oxaliplatin was tested by studying the expression of ERCC1, which encodes a DNA-excision repair protein. According to a previous study, high expression of ERCC1 was correlated with resistance to platinum compounds, which inhibit DNA synthesis by forming DNA crosslinks [26].

According to the present study, the administration of either the agents in a single high-concentration or in metronomic application, did not cause significant impact in their phenotype. The only remarkable is the effect of metronomic application in colon CSCs after 144, 192 and $240 \mathrm{~h}$ of incubation. Under these conditions, the cells failed to form the matrix they had previously. Previous data supported the hypothesis that CSCs and cancer cells might have similar mechanisms of chemoresistance. Furthermore, a correlation between epithelial to mesenchymal transition (EMT) and CSCs also occurred. This process, which characterized by morphological changes from epithelium to mesenchyme as well as decreased intercellular contact, and increased cellular motility, might be implicated to cell resistance anf formation [27] [28].

Concerning the growth inhibition, there were no clear differences between the different chemotherapy applications in HCT-116 cells. The higher impact was after $192 \mathrm{~h}$ of incubation. In colon CSCs, the effect was greater after 144, 192 and $240 \mathrm{~h}$ of incubation, but between the two types of administration the differences were not statistically significant. These findings support those of previous studies, which concluded that metronomic 5-FU and oxaliplatin chemotherapy may not be appropriate in all cases of CRC [29].

Regarding the gene expression levels in CRC cell line, the decrease in gene expression was higher, in most of the cases, for the combination of 5-FU-OXA when these administered metronomically. On the other hand, the single high-administration was more effective in colon CSCs.

\section{Conclusion}

In conclusion, the present experimental data provide no strong evidence to suggest that metronomic drug application is more effective than administration of a single maximum tolerated concentration. Although specific genes associated with 5-FU and oxaliplatin resistance were reduced by metronomic treatment, single-use treatment appeared to be more effective in colon CSCs. The chemotherapy regimen therefore needs to be chosen carefully to minimize the risk of side effects. It is possible that metronomic chemotherapy may be preferable for 
initial treatment, followed by subsequent single-dose chemotherapy. Further clinical studies are needed to confirm the above results.

\section{References}

[1] Siegel, R., Desantis, C. and Jemal, A. (2014) Colorectal Cancer Statistics, 2014. CA: A Cancer Journal for Clinicians, 64, 104-117. http://dx.doi.org/10.3322/caac.21220

[2] Cunningham, D., Atkin, W., Lenz, H.J., Lynch, H.T., Minsky, B., Nordlinger, B. and Starling, N. (2010) Colorectal Cancer. Lancet, 375, 1030-1047. http://dx.doi.org/10.1016/S0140-6736(10)60353-4

[3] Chau, I. and Cunningham, D. (2002) Adjuvant Therapy in Colon Cancer: Current Status and Future Directions. Cancer Treatment Reviews, 28, 223-236. http://dx.doi.org/10.1016/S0305-7372(02)00047-6

[4] Shim, B.Y., Lee, K.M., Cho, H.M., Kim, H.J., Cho, H.J., Yang, J., Kim, J.G. and Kim, H.K. (2005) Oxaliplatin/5-FU without Leucovorin Chemotherapy in Metastatic Colorectal Cancer. Cancer Research and Treatment, 37, 212-215. http://dx.doi.org/10.4143/crt.2005.37.4.212

[5] Toloudi, M., Apostolou, P. and Papasotiriou, I. (2015) Efficacy of 5-FU or Oxaliplatin Monotherapy over Combination Therapy in Colorectal Cancer. Journal of Cancer Therapy, 6, 345-355. http://dx.doi.org/10.4236/jct.2015.64037

[6] Kerbel, R.S. and Kamen, B.A. (2004) The Anti-Angiogenic Basis of Metronomic Chemotherapy. Nature Reviews Cancer, 4, 423-436. http://dx.doi.org/10.1038/nrc1369

[7] Hermann, P.C., Huber, S.L., Herrler, T., Aicher, A., Ellwart, J.W., Guba, M., Bruns, C.J. and Heeschen, C. (2007) Distinct Populations of Cancer Stem Cells Determine Tumor Growth and Metastatic Activity in Human Pancreatic Cancer. Cell Stem Cell, 1, 313-323. http://dx.doi.org/10.1016/j.stem.2007.06.002

[8] Toloudi, M., Apostolou, P., Chatziioannou, M. and Papasotiriou, I. (2011) Correlation between Cancer Stem Cells and Circulating Tumor Cells and Their Value. Case Reports in Oncology, 4, 44-54. http://dx.doi.org/10.1159/000324403

[9] Gradilone, A., Naso, G., Raimondi, C., Cortesi, E., Gandini, O., Vincenzi, B., Saltarelli, R., Chiapparino, E., Spremberg, F., Cristofanilli, M., et al. (2011) Circulating Tumor Cells (CTCs) in Metastatic Breast Cancer (MBC): Prognosis, Drug Resistance and Phenotypic Characterization. Annals of Oncology, 22, 86-92. http://dx.doi.org/10.1093/annonc/mdq323

[10] Dean, M. (2009) ABC Transporters, Drug Resistance, and Cancer Stem Cells. Journal of Mammary Gland Biology and Neoplasia, 14, 3-9. http://dx.doi.org/10.1007/s10911-009-9109-9

[11] Livak, K.J. and Schmittgen, T.D. (2001) Analysis of Relative Gene Expression Data Using Real-Time Quantitative PCR and the 2(-Delta Delta C(T)) Method. Methods, 25, 402-408. http://dx.doi.org/10.1006/meth.2001.1262

[12] Jemal, A., Bray, F., Center, M.M., Ferlay, J., Ward, E. and Forman, D. (2011) Global Cancer Statistics. CA: A Cancer Journal for Clinicians, 61, 69-90. http://dx.doi.org/10.3322/caac.20107

[13] Sahlberg, S.H., Spiegelberg, D., Glimelius, B., Stenerlow, B. and Nestor, M. (2014) Evaluation of Cancer Stem Cell Markers CD133, CD44, CD24: Association with AKT Isoforms and Radiation Resistance in Colon Cancer Cells. PLoS ONE, 9, e94621. http://dx.doi.org/10.1371/journal.pone.0094621

[14] Liu, G., Yuan, X., Zeng, Z., Tunici, P., Ng, H., Abdulkadir, I.R., Lu, L., Irvin, D., Black, K.L. and Yu, J.S. (2006) Analysis of Gene Expression and Chemoresistance of CD133 ${ }^{+}$Cancer Stem Cells in Glioblastoma. Molecular Cancer, 5, 67. http://dx.doi.org/10.1186/1476-4598-5-67

[15] Scharovsky, O.G., Mainetti, L.E. and Rozados, V.R. (2009) Metronomic Chemotherapy: Changing the Paradigm That More Is Better. Current Oncology, 16, 7-15. http://dx.doi.org/10.3747/co.v16i2.420

[16] Vives, M., Ginesta, M.M., Gracova, K., Graupera, M., Casanovas, O., Capella, G., Serrano, T., Laquente, B. and Vinals, F. (2013) Metronomic Chemotherapy Following the Maximum Tolerated Dose Is an Effective Anti-Tumour Therapy Affecting Angiogenesis, Tumour Dissemination and Cancer Stem Cells. International Journal of Cancer, 133, 2464-2472. http://dx.doi.org/10.1002/ijc.28259

[17] Sperone, P., Ferrero, A., Daffara, F., Priola, A., Zaggia, B., Volante, M., Santini, D., Vincenzi, B., Badalamenti, G., Intrivici, C., et al. (2010) Gemcitabine plus Metronomic 5-Fluorouracil or Capecitabine as a Second-/Third-Line Chemotherapy in Advanced Adrenocortical Carcinoma: A Multicenter Phase II Study. Endocrine-Related Cancer, 17, 445453. http://dx.doi.org/10.1677/ERC-09-0281

[18] Murakami, H., Ogata, Y., Akagi, Y., Ishibashi, N. and Shirouzu, K. (2011) Circulating Endothelial Progenitor Cells in Metronomic Chemotherapy Using Irinotecan and/or Bevacizumab for Colon Carcinoma: Study of Their Clinical Significance. Experimental and Therapeutic Medicine, 2, 595-600.

[19] Hackl, C., Man, S., Francia, G., Milsom, C., Xu, P. and Kerbel, R.S. (2013) Metronomic Oral Topotecan Prolongs Survival and Reduces Liver Metastasis in Improved Preclinical Orthotopic and Adjuvant Therapy Colon Cancer Models. Gut, 62, 259-271. http://dx.doi.org/10.1136/gutjnl-2011-301585 
[20] Yoshikawa, R., Kusunoki, M., Yanagi, H., Noda, M., Furuyama, J.I., Yamamura, T. and Hashimoto-Tamaoki, T. (2001) Dual Antitumor Effects of 5-Fluorouracil on the Cell Cycle in Colorectal Carcinoma Cells: A Novel Target Mechanism Concept for Pharmacokinetic Modulating Chemotherapy. Cancer Research, 61, 1029-1037.

[21] Longley, D.B., Harkin, D.P. and Johnston, P.G. (2003) 5-Fluorouracil: Mechanisms of Action and Clinical Strategies. Nature Reviews Cancer, 3, 330-338. http://dx.doi.org/10.1038/nrc1074

[22] Jensen, S.A., Vainer, B., Witton, C.J., Jorgensen, J.T. and Sorensen, J.B. (2008) Prognostic Significance of Numeric Aberrations of Genes for Thymidylate Synthase, Thymidine Phosphorylase and Dihydrofolate Reductase in Colorectal Cancer. Acta Oncologica, 47, 1054-1061. http://dx.doi.org/10.1080/02841860801942158

[23] Ichikawa, W., Uetake, H., Shirota, Y., Yamada, H., Nishi, N., Nihei, Z., Sugihara, K. and Hirayama, R. (2003) Combination of Dihydropyrimidine Dehydrogenase and Thymidylate Synthase Gene Expressions in Primary Tumors as Predictive Parameters for the Efficacy of Fluoropyrimidine-Based Chemotherapy for Metastatic Colorectal Cancer. Clinical Cancer Research, 9, 786-791.

[24] Steck, S.E., Keku, T., Butler, L.M., Galanko, J., Massa, B., Millikan, R.C. and Sandler, R.S. (2008) Polymorphisms in Methionine Synthase, Methionine Synthase Reductase and Serine Hydroxymethyltransferase, Folate and Alcohol Intake, and Colon Cancer Risk. Journal of Nutrigenetics and Nutrigenomics, 1, 196-204. http://dx.doi.org/10.1159/000136651

[25] DiPaolo, A. and Chu, E. (2004) The Role of Thymidylate Synthase as a Molecular Biomarker. Clinical Cancer Research, 10, 411-412. http://dx.doi.org/10.1158/1078-0432.CCR-1198-03

[26] Yu, Y., Kanwar, S.S., Patel, B.B., Nautiyal, J., Sarkar, F.H. and Majumdar, A.P. (2009) Elimination of Colon Cancer Stem-Like Cells by the Combination of Curcumin and FOLFOX. Translational Oncology, 2, 321-328. http://dx.doi.org/10.1593/tlo.09193

[27] Kim, Y., Joo, K.M., Jin, J. and Nam, D.H. (2009) Cancer Stem Cells and Their Mechanism of Chemo-Radiation Resistance. International Journal of Stem Cells, 2, 109-114. http://dx.doi.org/10.15283/ijsc.2009.2.2.109

[28] Hollier, B.G., Evans, K. and Mani, S.A. (2009) The Epithelial-to-Mesenchymal Transition and Cancer Stem Cells: A Coalition against Cancer Therapies. Journal of Mammary Gland Biology and Neoplasia, 14, 29-43. http://dx.doi.org/10.1007/s10911-009-9110-3

[29] Fioravanti, A., Canu, B., Ali, G., Orlandi, P., Allegrini, G., Di Desidero, T., Emmenegger, U., Fontanini, G., Danesi, R., Del Tacca, M., et al. (2009) Metronomic 5-Fluorouracil, Oxaliplatin and Irinotecan in Colorectal Cancer. European Journal of Pharmacology, 619, 8-14. http://dx.doi.org/10.1016/j.ejphar.2009.08.020 